\title{
Which pathways trigger the role of complement in ischemia/reperfusion injury?
}

\author{
Conrad A. Farrar ${ }^{1}$, Elham Asgari ${ }^{1}$, Wilhelm J. Schwaeble ${ }^{2}$ and Steven H. Sacks ${ }^{1}$ * \\ ' MRC Centre for Transplantation, Division of Transplantation Immunology and Mucosal Biology, King's College London School of Medicine at Guy's, King's \\ College and St Thomas' Hospitals, London, UK \\ ${ }^{2}$ Department of Infection, Immunity, and Inflammation, Leicester University, Leicester, UK
}

\author{
Edited by: \\ Claudia Kemper, King's College \\ London, UK \\ Reviewed by: \\ Michael Kirschfink, University of \\ Heidelberg, Germany \\ Arvind Sahu, National Centre for Cell \\ Science, India \\ ${ }^{*}$ Correspondence: \\ Steven H. Sacks, MRC Centre for \\ Transplantation, Division of \\ Transplantation Immunology and \\ Mucosal Biology, King's College \\ London School of Medicine at Guy's, \\ King's College and St Thomas' \\ Hospitals, 5th Floor Tower Wing, \\ London, UK. \\ email: steven.sacks@kcl.ac.uk
}

Investigations into the role of complement in ischemia/reperfusion (I/R) injury have identified common effector mechanisms that depend on the production of C5a and C5b-9 through the cleavage of C3. These studies have also defined an important role for C3 synthesized within ischemic kidney. Less clear however is the mechanism of complement activation that leads to the cleavage of $\mathrm{C} 3$ in ischemic tissues and to what extent the potential trigger mechanisms are organ dependent - an important question which informs the development of therapies that are more selective in their ability to limit the injury, yet preserve the other functions of complement where possible. Here we consider recent evidence for each of the three major pathways of complement activation (classical, lectin, and alternative) as mediators of I/R injury, and in particular highlight the role of lectin molecules that increasingly seem to underpin the injury in different organ models and in addition reveal unusual routes of complement activation that contribute to organ damage.

Keywords: ischemia, reperfusion, MBL, kidney, complement

\section{INTRODUCTION}

Complement is a member of the innate immune system and is comprised of both soluble proteins and membrane-bound receptors that are activated following invasion of foreign pathogens. The effector molecules that are generated have diverse biological activities, namely, defense against bacterial infection through opsonization; activation of leukocytes; removal of immune complexes and apoptotic cells (Janeway and Medzhitov, 2002); and the augmentation of B cell and T cell-mediated immunity (Pratt et al., 2002; Lee et al., 2005). However, it has clearly been demonstrated over a number of years that complement activation has a deleterious effect in a number of inflammatory conditions, including the rejection of solid organ transplants - effects that have been described in a number of organs, such as the lung, liver, heart, and kidney (Weisman et al., 1990; Eppinger et al., 1997; Zhou et al., 2000; Lehmann et al., 2001).

There are three different pathways that initiate the complement cascade, namely the classical, alternative, and the lectin pathways. The classical pathway is initiated once antibody-antigen complexes bind the classical pathway recognition subcomponent $\mathrm{C} 1 \mathrm{q}$, which forms the multimolecular $\mathrm{C} 1$ complex with the classical pathway-specific serine proteases $\mathrm{C} 1 \mathrm{r}$ and $\mathrm{C} 1 \mathrm{~s}$. The alternative pathway is activated by distinct carbohydrate or lipid motifs on pathogens or altered self molecules, leading to recruitment of C3 and factor B. Mannan-binding lectin (MBL) is one of five different lectin pathway-specific carbohydrate recognition molecules in man that associate with lectin pathway-specific serine proteases to drive complement activation. MBL shares a high degree of structural homology with $\mathrm{C} 1$, the multimolecular complex that initiates the classical activation pathway of complement. MBL binds to carbohydrate residues on microorganisms, or altered-self endogenous ligands that arise in pathological conditions such as ischemia/reperfusion (I/R) injury. MBL forms complexes with MBL-associated serine proteases (MASPs), which share a high degree of structural homology with the classical pathway serine proteases $\mathrm{C} 1 \mathrm{r}$ and $\mathrm{C} 1 \mathrm{~s}$. Three different forms of MASPs (MASP1, MASP-2, and MASP-3) have been described, and of those, MASP-1 and MASP-3 are encoded by a single structural gene (Thiel, 2007). When lectin pathway activation complexes bind to microbial carbohydrates or acetylated ligands, MASP-1 and MASP-2 are converted into their enzymatic active form. Of those, only MASP- 2 can translate binding into complement activation, by subsequent cleavage of the complement components $\mathrm{C} 4$ and C4b-bound $\mathrm{C} 2$, to form the lectin pathway C3 and C5 convertase complexes $\mathrm{C} 4 \mathrm{~b} 2 \mathrm{a}$ and $\mathrm{C} 4 \mathrm{~b} 2 \mathrm{a}(\mathrm{C} 3 \mathrm{~b})_{\mathrm{n}}$ respectively. MASP-1 can cleave $\mathrm{C} 4 \mathrm{~b}$-bound $\mathrm{C} 2$, but not $\mathrm{C} 4$, therefore the lectin pathway activation route is deficient in the absence of MASP-2 (Schwaeble et al., 2011). MASP-1 can augment MASP-2 functional activity by cleaving C2 and possibly enhancing complement activation by conversion of MASP-2 into the enzymatic active form, but it cannot compensate for the loss of MASP-2 functional activity. A recent study using MASP-1-specific inhibitory peptides implies an essential role of MASP-1 in aiding the activation of MASP-2 (Heja et al., 2012), a hypothesis that is not supported by the phenotype of serum of MASP-1 and MASP-3-deficient mice, as this serum clearly shows reduced but marked lectin pathway functional activity mediated by residual MASP-2 (Schwaeble et al., 2011). The convergence point of all three pathways is the activation of C3, an abundant plasma component that is converted into $\mathrm{C} 3 \mathrm{a}$ and $\mathrm{C} 3 \mathrm{~b}$ via a $\mathrm{C} 3$ convertase, a process that leads to the 
subsequent formation of membrane attack complexes. Though the liver is the main site of complement C3 synthesis (Alper et al., 1969), a wide range of soluble complement proteins, including C3, are also produced by extra-hepatic synthesis. The synthesis of many soluble complement proteins in a variety of cells and tissues is comprehensively outlined in a recent review (Li et al., 2007). The purpose of this article is to focus on the role of complement in inflamed whole organs, particularly transplanted ischemic kidney, with emphasis on emerging knowledge of the relative contribution of the complement activation pathways to tissue injury.

\section{RENAL I/R INJURY}

Ischemia/reperfusion injury manifests rapidly and is the product of tissue hypoxia and production of free radicals following the introduction of oxygenated blood to an oxygen-deprived kidney (Grace, 1994). The tissue architecture of an ischemic organ has significant bearing on the nature of the inflammatory reaction that mediates damage. In ischemic kidney the primary area of complement-mediated attack appears to be the tubulointerstitium within the corticomedullary junction (Bonventre, 1993). Here, significant tubulo-interstitial damage via the alternative pathway of complement activation has been demonstrated in both native kidney (Zhou et al., 2000) and human transplanted kidney (Thurman et al., 2005). In both rodent renal allografts and syngeneic grafts, reperfusion injury affects the proximal tubules in the corticomedullary region (Pratt et al., 2000; Farrar et al., 2006).

\section{LOCAL RENAL COMPLEMENT PROTEIN EXPRESSION RENAL SYNTHESIS OF COMPLEMENT PATHWAY COMPONENTS}

Following ischemic insult and subsequent reperfusion, renal cells targeted by complement activation are also capable of significant complement protein biosynthesis themselves. Complement C3 and/or C4 can be expressed by proximal tubular epithelial cells (Brooimans et al., 1991), glomerular epithelial cells (Sacks et al., 1993; Zhou et al., 1993), endothelial cells (Sheerin et al., 1997), and glomerular mesangial cells (Sacks et al., 1993). Complement proteins can be produced by the liver in large amounts, which raises a question as to the significance of local renal complement production during renal transplantation. It can be speculated that local production by both resident cells (Sacks et al., 1993) and infiltrating leukocytes (Botto et al., 1992) enhances the speed of reaction leading to an inflammatory response and tissue damage following reperfusion insult. Additionally, tissue-specific regulation of complement proteins at sites of inflammation may confer advantages over peripheral gene expression. This idea is given credence by the observation that interleukin-1 (IL-1) can potently stimulate renal complement production in the absence of any effect on hepatic synthesis (Falus et al., 1987). In fact, most of the complement proteins of both the classical and alternative activation pathways can be produced within the kidney (Passwell et al., 1988; Song et al., 1998). To date, only hepatocytes have been shown to synthesize MBL, except for the rat, in which extra-hepatic expression of MBL protein has been reported within the renal corpuscle and distal tubules of the kidney (Morio et al., 1997). It has also been detected in the small intestine of mice (Wagner et al., 2003), whereas the biosynthesis of MASP-2 strictly occurs in hepatocytes and is undetectable in any extra-hepatic tissue (Stover et al., 2004).

\section{COMPLEMENT REGULATORY PROTEINS EXPRESSED WITHIN THE KIDNEY}

Regulators of complement activation are expressed on most cells and tissues, providing crucial protection from autologous complement activation and deposition. These complement control proteins are expressed in a variety of renal cells (Nangaku, 1998) and include proteins such as CD46 (membrane cofactor protein; $\mathrm{MCP}$ ) and CD55 (decay accelerating factor; DAF). DAF functions by enhancing the dissociation of $\mathrm{Bb} / \mathrm{C} 2 \mathrm{a}$ from $\mathrm{C} 3$ convertases and MCP acts as a cofactor for factor I-mediated cleavage of $\mathrm{C} 3 \mathrm{~b}$ and $\mathrm{C} 4 \mathrm{~b}$. Both regulatory components target the activity of every C3 and C5 convertase complex containing either C3b or C4b. Under physiological circumstances MCP and DAF prevent excessive activation of complement, and it is of interest to note that the hypoxia-sensitive renal corticomedullary junction displays low expression of DAF (Cosio et al., 1989). This may go some way to explaining why this region of the kidney is particularly susceptible to complement-mediated attack. Rodent complement regulator Crry, a homologue of human CR1 (Quigg et al., 1998) is expressed within the corticomedullary junction. Under inflammatory conditions associated with ischemia and reperfusion in native kidney, Crry expression re-polarizes from the basolateral surface of the renal tubules to within the tubule lumen (Thurman et al., 2006), exposing tubules to complement-mediated attack. An increase in C3 mRNA expression was also observed, suggesting that loss of complement regulation and/or increased local complement production contributes to the pathogenesis of reperfusion injury (Thurman etal., 2006). A more closely defined role for locally-expressed Crry using Crry-deficient kidneys has been identified. When transplanted into Crry-sufficient recipients, deficient kidneys are subject to more severe renal damage, exemplified by unrestricted C3 activation, increased tubular damage and fibrosis, with a significant influx of polymorphonuclear cells (Bao et al., 2007). More recently it has been demonstrated that interaction of complement regulator factor $\mathrm{H}$ with the surface of tubular epithelial cells is required to curb complement deposition following renal I/R injury, as mice treated with an inhibitor of factor $\mathrm{H}$ displayed severe tubular injury (Renner et al., 2011).

\section{EFFECTORS OF COMPLEMENT-MEDIATED DAMAGE FOLLOWING RENAL ISCHEMIA/REPERFUSION INSULT}

In renal transplantation, organ reperfusion and cell-mediated immune mechanisms directed at the kidney, as well as invasion by bacteria, are associated with worse transplant outcome. These pathological conditions predominantly affect the renal tubules, where there is significant complement deposition. In native kidney, animals with individual deficiency of C3, C5, or C6, demonstrated significant reduction in reperfusion damage, with corresponding reduction in renal failure (Zhou et al., 2000). The most striking protective effect was seen in the absence of $\mathrm{C} 3$, and further studies in the absence of C5 or C6 suggested that reperfusion injury is dependent on the formation of the lytic effector molecule MAC (Zhou et al., 2000). Indeed, further evidence supports a role for 
both effectors $\mathrm{C} 5 \mathrm{a}$ and $\mathrm{MAC}$ formation in mouse renal reperfusion injury (Arumugam et al., 2003; de Vries et al., 2003).

\section{LOCALLY PRODUCED C3 IN I/R INJURY}

Regarding the contribution of locally produced $\mathrm{C} 3$ within the kidney, C3 mRNA is up-regulated within $2 \mathrm{~h}$ of reperfusing ischemic rat kidney (Takada et al., 1997). Kidney swap experiments between complement C3-sufficient and C3-deficient mice have been informative. It was demonstrated that locally synthesized C3, produced by and deposited on the basolateral surface of proximal tubule cells, was essential for complement-mediated reperfusion injury in transplanted kidney (Farrar et al., 2006). Significant involvement of circulating $\mathrm{C} 3$ was not observed, a phenomenon that could indicate poor penetration of hepatic C3 (C3 is a $180-\mathrm{kD}$ protein), and/or an excessive production of complement within the inflamed kidney. Indeed, the period of cold ischemia is closely associated with an increase in renal C3 mRNA (Pratt et al., 2000; Farrar et al., 2006). It is worth noting that the effect of local renal C3 production is still observed in allograft models, but it is difficult to disentangle the effects of $\mathrm{C} 3$ on allograft rejection from those associated with I/R injury alone (Pratt et al., 2002).

\section{WHICH ARE THE MAIN COMPLEMENT ACTIVATION TRIGGER PATHWAYS IN WHOLE ORGAN I/R INJURY?}

Since C3 has been shown to be essential for the formation of C5a and C5b-9 in animal models of reperfusion injury, a key question concerns the trigger pathways that lead to the cleavage of $\mathrm{C} 3$ at the affected tissue site. Studies in several organ models (of I/R damage) have yielded potentially conflicting results about the contribution of different pathways to the cleavage of C3. Here we review the evidence for involvement of classical, lectin and alternative pathway activity, which highlights an emerging role for lectin pathway activation.

\section{SKELETAL AND INTESTINAL I/R INJURY}

In skeletal muscle and the intestine, I/R injury is associated with marked complement activation and endothelial cell damage within the vasculature and subsequent tissue necrosis (Weiser etal., 1996; Zhao etal., 2002). Limited injury was observed in an intestinal reperfusion injury model suggesting a dependency on C2, MBL and activation of the lectin pathway for injury, with no significant contribution from $\mathrm{Clq}$ and classical pathway activation or alternative pathway involvement (Hart et al., 2005). However, findings in a similar animal model of intestinal reperfusion injury suggested that the observed damage was dependent upon IgM-mediated activation of the classical pathway (Williams et al., 1999; Zhang et al., 2004). Recently, a more detailed understanding of the mechanism of lectin pathway activation in intestinal I/R injury has been described (Zhang et al., 2006), in which MBL was shown to bind naturally occurring IgM at the site of injury, leading to lectin pathway activation with no involvement of the classical pathway. Furthermore, in a study of skeletal reperfusion injury, it was initially suggested that inflammation was mediated exclusively through an effect of classical pathway activation (Weiser et al., 1996). However, with the availability of both C1q-deficient mice and MBL-deficient mice, it now seems clear that activation of both lectin and classical pathways is responsible for the range of inflammatory responses observed. Muscle injury is dependent on lectin pathway activation, with remote pulmonary injury and vascular permeability (manifest by edema), being dependent on classical pathway activation (Chan et al., 2006). It has been conclusively demonstrated by surface plasmon resonance that human MBL binds IgM and subsequent treatment of human endothelial cells in vitro with IgM, MBL and MASP-2 directly activated and deposited C4 (McMullen et al., 2006). More recently, using the same model of intestinal I/R injury as described earlier (Zhang et al., 2006), in which the mesenteric artery is clamped, tissue injury was more firmly attributed to activation of the lectin pathway, as MBL was present in association with naturally occurring IgM. The injury was not mediated by alternative pathway activation when the same injury protocol was applied to factor B knockout mice (Lee et al., 2010). This naturallyoccurring antibody was earlier found to be a self-reactive IgM capable of mediating intestinal reperfusion injury (Zhang et al., 2004). Presence of this IgM has led to the discovery of two distinct self-antigens (ischemia-specific antigens), namely type A and C non-muscle myosin heavy chain (NMHC-II; Zhang et al., 2006) and more recently, actin cytoskeleton has been shown to bind IgM during ischemia, leading to reperfusion injury (Shi et al., 2009). These recent observations are very exciting as they have uncovered a previously unresolved role for IgM in intestinal reperfusion injury, the hallmark of which is characterized by binding of IgM to endogenous ligands exposed upon injury, with direct activation of the lectin pathway without involvement of the classical pathway.

\section{MYOCARDIAL I/R INJURY}

An association of both $\mathrm{C} 3$ and MBL deposition in ischemic rodent heart was observed over a decade ago (Collard et al., 2000). Subsequently, it was shown that blockade of rat MBL with a therapeutic antibody reduced the extent of myocardial reperfusion injury (Jordan et al., 2001). Moreover, MBL deficiency conferred protection from injury, whereas classical pathway activation appeared not to be involved in mediating injury, as Clq-deficient mice were not protected (Walsh et al., 2005). This finding echoed observations in the intestine, where presence of C1q-mediated classical pathway activation was not a requirement for injury (Hart et al., 2005). Further insight into the mechanisms causing myocardial reperfusion injury was provided through reconstitution experiments in triple knockout mice, in which injury was dependent upon both naturally occurring IgM and MBL-mediated complement activation (Busche et al., 2009). Of particular interest is the observation that diabetic patients, who are at risk of cardiomyopathy, may benefit from transient blockade of MBL, as MBL-knockout mice are protected from diabetes-induced myocardial reperfusion injury (Busche et al., 2008). Interestingly, as in $\mathrm{I} / \mathrm{R}$ injury of the intestine, it is emerging that there is significant contribution to pathophysiology through an interaction between naturally-occurring IgM and lectin pathway activation (Busche et al., 2009).

\section{KIDNEY I/R INJURY}

That C3 is a crucial mediator of renal reperfusion injury is not in dispute. This seems unsurprising, given that $\mathrm{C} 3$ is the central protein of the complement cascade, the point of convergence for all 
three recognized activation pathways. Classical pathway activation is currently not regarded as a requirement for renal reperfusion injury, as it has been demonstrated that injury is independent of both IgG and IgM (Park et al., 2002) and deficiency of C4 was non-protective both in native kidney (Zhou et al., 2000) and renal transplant models (Lin et al., 2006) in the mouse. An absence of classical pathway activation in the kidney is perhaps not surprising as it seems unlikely that there would be adequate transfer of $\operatorname{IgM}$ from the renal capillaries to the interstitium, the principle target of reperfusion injury. Damage within the kidney is manifest by significant MAC deposition that was curtailed in the absence of C3 (Zhou et al., 2000). This MAC deposition hinted at the involvement of alternative pathway activation as a mediator of renal reperfusion injury. In addition, no protective effect was found in the complete absence of $\mathrm{C} 4$, suggesting that the phenotypic injury did not result from classical or lectin pathway activation, since $\mathrm{C} 4$ is common to both (Zhou et al., 2000). However, the recent discovery that the lectin pathway shows residual functional activity in C4-deficient mouse and human sera may explain the persistence of complement-mediated I/R injury in C4-deficient subjects (Schwaeble et al., 2011). A role for contribution of the alternative activation pathway was demonstrated in factor B knockout mice, which were afforded significant protection from reperfusion injury when compared to mice replete with factor B (Thurman et al., 2003). Lectin pathway involvement in renal reperfusion injury was suggested following a study in which both mouse kidney (damaged by I/R injury) and human renal transplant biopsies displayed significant deposition of MBL-A and MBL-C, components that were found to co-localize with complement C3 (de Vries et al., 2004). Using transgenic mice deficient in both MBL-A and MBL$\mathrm{C}$, contribution of lectin pathway activation to renal I/R injury was demonstrated (Moller-Kristensen et al., 2005). The observed protective phenotype was readily reversed following reconstitution of the mutant mice with recombinant MBL (Moller-Kristensen et al., 2005). In a pig model, inhibition of classical and lectin activation pathways following the administration of recombinant human $\mathrm{C1}$ inhibitor ( $\mathrm{rClINH})$, conferred protection from renal reperfusion injury (Castellano et al., 2010). Components of the lectin pathway (MBL and MASP-2) were abundantly deposited in the damaged kidney, with sparse $\mathrm{C} 1 \mathrm{q}$ deposition, suggesting a predominance of lectin pathway activity (Castellano et al., 2010). More recently, an entirely new concept of lectin pathway participation in renal reperfusion injury suggested that $\mathrm{MBL}$ is internalized by damaged tubules which are then subject to apoptosis through an MBLmediated mechanism. This injury was found to be independent of an effect of complement (van der Pol et al., 2012).

\section{UNORTHODOX ROUTES OF COMPLEMENT ACTIVATION VIA LECTIN PATHWAY IN I/R INJURY}

As most recently described (Turner, 2003), there has been significant interest in the contribution of the lectin pathway to I/R injury. In models of intestinal, skeletal and renal I/R injury, significant contribution of the lectin activation pathway was observed. It is of particular interest that the lectin pathway may trigger inflammatory responses within the pathophysiology of I/R injury by unconventional and as yet undefined bypass activation events. This may have an impact on our current understanding of the mechanism of lectin pathway activation in reperfusion injury. Although C4 is traditionally considered a requirement for lectin pathway-mediated cleavage of C3 (Thiel et al., 1997; Vorup-Jensen et al., 2000), there is clear evidence for the existence of so called "bypass" pathway activation events, leading to residual activation in the absence of certain cascade components caused by inherited or gene-targeted deficiencies (Degn et al., 2007). The existence of a C4-bypass pathway was first reported in C4-deficient guinea pig serum (May and Frank, 1973). Recent work has provided remarkable insight into the role of lectin pathway components in models of both cardiac and intestinal I/R injury in mice (Schwaeble et al., 2011). In both pathological states, injury was induced via MASP-2mediated lectin pathway activation. The report also demonstrated that $\mathrm{C} 4$ was not required, suggesting the presence of a previously unrecognized C4-independent MASP-2-dependent bypass route of lectin pathway cleavage of $\mathrm{C} 3$. These findings may explain the lack of protection of $\mathrm{C} 4$ deficiency in both native renal ischemia and the model of renal allograft rejection discussed earlier (Zhou et al., 2000; Lin etal., 2006). This C4-independent MASP-2dependent bypass mechanism has recently has been confirmed in a renal transplant model (Farrar et al., 2009). Importantly, these recent findings in different organ models of I/R injury highlight MASP-2 as an early trigger point in a specific complement activation pathway, which may prove to be an attractive therapeutic target in ischemic inflammatory settings. As to the role of MASP1 or MASP-3 in complement-mediated I/R injury, gene-targeted mice deficient of both MASP-1 and MASP-3 are not protected from injury, indicating that neither MASP-1, nor MASP-3 contribute to MASP-2-dependent reperfusion injury (W. Schwaeble, unpublished data).

\section{MBL AND LECTIN PATHWAY OF COMPLEMENT ACTIVATION IN HUMANS}

A link between deficiency of MBL and susceptibility to infection in both man and rodents has been established (Eisen and Minchinton, 2003; Shi etal., 2004). In experimental models of renal reperfusion injury, MBL deficiency in rodents (Moller-Kristensen etal., 2005) and lectin pathway inhibition in pigs (Castellano et al., 2010) led to improved renal function. In human transplant recipients suffering from delayed graft function (DGF) after transplantation, there was a positive association with MBL pathway products (de Vries et al., 2004). Moreover, in human kidney transplantation, genetically-determined low levels of pre-transplant serum MBL correlated with significantly improved transplant outcome (Berger et al., 2005). A similar study looking at simultaneous pancreas and renal transplantation again found that low levels of circulating MBL correlated with improved long-term kidney survival (Berger et al., 2007). However, a recent study of a large cohort of donor and recipient MBL and MASP-2 genotypes failed to confirm a link between genotype and allograft function following kidney transplantation (Damman et al., 2012). Hence to date, from a limited number of studies in humans, there is no conclusive agreement upon the importance of genetic variation of lectin pathway components in ischemic renal allografts, although this remains a subject of much interest as a possible means to stratify patient groups according to expected outcome of the transplant. 


\section{CONCLUDING REMARKS}

This brief overview of the role of complement activation in the pathogenesis of whole organ ischemia highlights a previously unrecognized predominant role of lectin molecules in several organ models of I/R injury. One possible trigger mechanism leading to activation of the lectin pathway is the binding of natural IgM to epitopes exposed on ischemic tissue, with no involvement of previously implicated classical pathway activation. The alternative pathway is implicated in some instances, for example following renal ischemia, and may serve to amplify the cleavage of $\mathrm{C} 3$ and subsequent evolution of injury, following initiation

\section{REFERENCES}

Alper, C. A., Johnson, A. M., Birtch, A. G., and Moore, F. D. (1969). Human C'3: evidence for the liver as the primary site of synthesis. Science 163, 286-288.

Arumugam, T. V., Shiels, I. A., Strachan, A. J., Abbenante, G., Fairlie, D. P., and Taylor, S. M. (2003). A small molecule C5a receptor antagonist protects kidneys from ischemia/reperfusion injury in rats. Kidney Int. 63, 134-142.

Bao, L., Wang, Y., Chang, A., Minto, A. W., Zhou, J., Kang, H., et al. (2007). Unrestricted C3 activation occurs in Crry-deficient kidneys and rapidly leads to chronic renal failure. J. Am. Soc. Nephrol. 18, 811-822.

Berger, S. P., Roos, A., Mallat, M. J., Schaapherder, A. F., Doxiadis, I. I., van Kooten, C., et al. (2007). Low pretransplantation mannosebinding lectin levels predict superior patient and graft survival after simultaneous pancreas-kidney transplantation. J. Am. Soc. Nephrol. 18, 2416-2422.

Berger, S. P., Roos, A., Mallat, M. J., Fujita, T., de Fijter, J. W., and Daha, M. R. (2005). Association between mannose-binding lectin levels and graft survival in kidney transplantation. Am. J. Transplant. 5, 13611366.

Bonventre, J. V. (1993). Mechanisms of ischemic acute renal failure. Kidney Int. 43, 1160-1178.

Botto, M., Lissandrini, D., Sorio, C., and Walport, M. J. (1992). Biosynthesis and secretion of complement component (C3) by activated human polymorphonuclear leukocytes. J. Immunol. 149, 1348-1355.

Brooimans, R. A., Stegmann, A. P., van Dorp, W. T., van der Ark, A. A., van der Woude, F. J., van Es, L. A., et al. (1991). Interleukin 2 mediates stimulation of complement C3 biosynthesis in human proximal tubular epithelial cells. J. Clin. Invest. 88, 379-384.

Busche, M. N., Walsh, M. C., McMullen, M. E., Guikema, B. J., and Stahl, G.
L. (2008). Mannose-binding lectin plays a critical role in myocardial ischaemia and reperfusion injury in a mouse model of diabetes. Diabetologia 51, 1544-1551.

Busche, M. N., Pavlov, V., Takahashi, K., and Stahl, G. L. (2009). Myocardial ischemia and reperfusion injury is dependent on both IgM and mannose-binding lectin. Am. J. Physiol. Heart Circ. Physiol. 297, H1853-H1859.

Castellano, G., Melchiorre, R., Loverre, A., Ditonno, P., Montinaro, V. Rossini, M., et al. (2010). Therapeutic targeting of classical and lectin pathways of complement protects from ischemia-reperfusion-induced renal damage. Am. J. Pathol. 176, 1648 1659.

Chan, R. K., Ibrahim, S. I., Takahashi, K., Kwon, E., McCormack, M., Ezekowitz, A., et al. (2006). The differing roles of the classical and mannose-binding lectin complement pathways in the events following skeletal muscle ischemia-reperfusion. J. Immunol. 177, 8080-8085.

Collard, C. D., Vakeva, A., Morrissey, M. A., Agah, A., Rollins, S. A., Reenstra, W. R., et al. (2000). Complement activation after oxidative stress: role of the lectin complement pathway. Am. J. Pathol. 156, 1549-1556.

Cosio, F. G., Sedmak, D. D., Mahan, J. D., and Nahman, N. S. Jr. (1989). Localization of decay accelerating factor in normal and diseased kidneys. Kidney Int. 36, 100-107.

Damman, J., Kok, J. L., Snieder, H., Leuvenink, H. G., van Goor, H., Hillebrands, J. L. et al. (2012). Lectin complement pathway gene profile of the donor and recipient does not influence graft outcome after kidney transplantation. Mol. Immunol. 50, $1-8$.

de Vries, B., Kohl, J., Leclercq, W. K., Wolfs, T. G., van Bijnen, A. A., Heeringa, P., et al. (2003). Complement factor C5a mediates renal ischemia-reperfusion injury independent from neutrophils. $J$. Immunol. 170, 3883-3889.

through the lectin pathway, or could be seen as an independent event. This prevalent role of lectin pathway activation makes it an attractive target for therapeutic intervention, with MASP-2 a potential candidate because of an absolute requirement of MASP-2 for lectin pathway activation in the pathogenesis of renal reperfusion injury. Although there are some conflicting results arising from early studies of the contribution of lectin pathway variants in the clinical setting, these findings do not preclude the investigation of therapeutic blockade of lectin pathway activation during the immediate post-transplant stage, where ischemic events have a significant impact upon renal allograft function.

de Vries, B., Walter, S. J., Peutz-Kootstra, C. J., Wolfs, T. G., van Heurn, L. W., and Buurman, W. A. (2004). The mannose-binding lectin-pathway is involved in complement activation in the course of renal ischemiareperfusion injury. Am. J. Pathol. 165, 1677-1688.

Degn, S. E., Thiel, S., and Jensenius, J. C. (2007). New perspectives on mannan-binding lectin-mediated complement activation. Immunobiology 212, 301-311.

Eisen, D. P., and Minchinton, R. M. (2003). Impact of mannose-binding lectin on susceptibility to infectious diseases. Clin. Infect. Dis. 37, 14961505.

Eppinger, M. J., Deeb, G. M., Bolling, S. F., and Ward, P. A. (1997). Mediators of ischemia-reperfusion injury of rat lung. Am. J. Pathol. 150, 1773-1784.

Falus, A., Beuscher, H. U., Auerbach, H. S., and Colten, H. R. (1987). Constitutive and IL 1-regulated murine complement gene expression is strain and tissue specific. J. Immunol. 138, 856-860.

Farrar, C. A., Asgari, E., Lynch, N., Roscher, S., Stover, C. M., Schwaeble, W. J., et al. (2009). Mannan binding lectin associated serine protease- 2 (MASP-2) is a critical player in the pathophysiology of renal ischaemia reperfusion (I/R) injury and mediates tissue injury in absence of complement C4. Mol. Immunol. 46, 2832.

Farrar, C. A., Zhou, W., Lin, T., and Sacks, S. H. (2006). Local extravascular pool of C3 is a determinant of postischemic acute renal failure. FASEB J. 20, 217-226.

Grace, P. A. (1994). Ischaemiareperfusion injury. Br. J. Surg. 81, 637-647.

Hart, M. L., Ceonzo, K. A., Shaffer, L. A., Takahashi, K., Rother, R. P., Reenstra, W. R., et al. (2005). Gastrointestinal ischemia-reperfusion injury is lectin complement pathway dependent without involving C1q. J. Immunol. 174, 6373-6380.

Heja, D., Kocsis, A., Dobo, J., Szilagyi, K., Szasz, R., Zavodszky, P., et al. (2012). Revised mechanism of complement lectin-pathway activation revealing the role of serine protease MASP-1 as the exclusive activator of MASP-2. Proc. Natl. Acad. Sci. U. S. A. 109, 10498-10503.

Janeway, C. A. Jr., and Medzhitov, R. (2002). Innate immune recognition. Annu. Rev. Immunol. 20, 197-216.

Jordan, J. E., Montalto, M. C., and Stahl, G. L. (2001). Inhibition of mannosebinding lectin reduces postischemic myocardial reperfusion injury. Circulation 104, 1413-1418.

Lee, H., Green, D. J., Lai, L., Hou, Y. J., Jensenius, J. C., Liu, D., et al. (2010). Early complement factors in the local tissue immunocomplex generated during intestinal ischemia/reperfusion injury. Mol. Immunol. 47, 972-981.

Lee, Y., Haas, K. M., Gor, D. O., Ding, X., Karp, D. R., Greenspan, N. S., et al. (2005). Complement component C3d-antigen complexes can either augment or inhibit B lymphocyte activation and humoral immunity in mice depending on the degree of CD21/CD19 complex engagement. J. Immunol. 175, 80118021

Lehmann, T. G., Koeppel, T. A., Munch, S., Heger, M., Kirschfink, M., Klar, E., et al. (2001). Impact of inhibition of complement by sCR1 on hepatic microcirculation after warm ischemia. Microvasc. Res. 62, 284-292.

Li, K., Sacks, S. H., and Zhou, W. (2007). The relative importance of local and systemic complement production in ischaemia, transplantation and other pathologies. Mol. Immunol. 44, 3866-3874.

Lin, T., Zhou, W., Farrar, C. A., Hargreaves, R. E., Sheerin, N. S., and Sacks, S. H. (2006). Deficiency of C4 from donor or recipient mouse fails to prevent renal allograft rejection. Am. J. Pathol. 168, 1241-1248.

May, J. E., and Frank, M. M. (1973). Hemolysis of sheep erythrocytes in guinea pig serum deficient in the fourth component of complement. I. 
Antibody and serum requirements. J. Immunol. 111, 1671-1677.

McMullen, M. E., Hart, M. L., Walsh, M. C., Buras, J., Takahashi, K., and Stahl, G. L. (2006). Mannose-binding lectin binds IgM to activate the lectin complement pathway in vitro and in vivo. Immunobiology 211, 759-766.

Moller-Kristensen, M., Wang, W., Ruseva, M., Thiel, S., Nielsen, S., Takahashi, K., et al. (2005). Mannanbinding lectin recognizes structures on ischaemic reperfused mouse kidneys and is implicated in tissue injury. Scand. J. Immunol. 61, 426-434.

Morio, H., Kurata, H., Katsuyama, R., Oka, S., Kozutsumi, Y., and Kawasaki, T. (1997). Renal expression of serumtype mannan-binding protein in rat. Eur. J. Biochem. 243, 770-774.

Nangaku, M. (1998). Complement regulatory proteins in glomerular diseases. Kidney Int. 54, 1419-1428.

Park, P., Haas, M., Cunningham, P. N., Bao, L., Alexander, J. J., and Quigg, R. J. (2002). Injury in renal ischemia-reperfusion is independent from immunoglobulins and $\mathrm{T}$ lymphocytes. Am. J. Physiol. Renal Physiol. 282, F352-F357.

Passwell, J., Schreiner, G. F., Nonaka, M., Beuscher, H. U., and Colten, H. R. (1988). Local extrahepatic expression of complement genes $\mathrm{C} 3$, factor $\mathrm{B}, \mathrm{C} 2$, and $\mathrm{C} 4$ is increased in murine lupus nephritis. J. Clin. Invest. 82, 1676-1684.

Pratt, J. R., Abe, K., Miyazaki, M., Zhou, W., and Sacks, S. H. (2000). In situ localization of C3 synthesis in experimental acute renal allograft rejection. Am. J. Pathol. 157, 825-831.

Pratt, J. R., Basheer S. A., and Sacks, S. H. (2002). Local synthesis of complement component $\mathrm{C} 3$ regulates acute renal transplant rejection. Nat. Med. 8, 582-587.

Quigg, R. J., He, C., Lim, A., Berthiaume, D., Alexander, J. J., Kraus, D., et al. (1998). Transgenic mice overexpressing the complement inhibitor Crry as a soluble protein are protected from antibody-induced glomerular injury. J. Exp. Med. 188, 1321-1331.

Renner, B., Ferreira, V. P., Cortes, C., Goldberg, R., Ljubanovic, D., Pangburn, M. K., et al. (2011). Binding of factor $\mathrm{H}$ to tubular epithelial cells limits interstitial complement activation in ischemic injury. Kidney Int. 80, 165-173.

Sacks, S. H., Zhou, W., Pani, A., Campbell, R. D., and Martin, J. (1993). Complement C3 gene expression and regulation in human glomerular epithelial cells. Immunology 79, 348-354.

Sacks, S., Zhou, W., Campbell, R. D., and Martin, J. (1993).
C3 and C4 gene expression and interferon-gamma-mediated regulation in human glomerular mesangial cells. Clin. Exp. Immunol. 93, 411-417.

Schwaeble, W. J., Lynch, N. J., Clark, J. E., Marber, M., Samani, N. J., Ali, Y. M., et al. (2011). Targeting of mannan-binding lectin-associated serine protease- 2 confers protection from myocardial and gastrointestinal ischemia/reperfusion injury. Proc. Natl. Acad. Sci. U.S.A. 108, 75237528.

Sheerin, N. S., Zhou, W., Adler, S., and Sacks, S. H. (1997). TNF-alpha regulation of $\mathrm{C} 3$ gene expression and protein biosynthesis in rat glomerular endothelial cells. Kidney Int. 51, 703-710.

Shi, L., Takahashi, K., Dundee, J., Shahroor-Karni, S., Thiel, S., Jensenius, J. C., et al. (2004). Mannosebinding lectin-deficient mice are susceptible to infection with Staphylococcus aureus. J. Exp. Med. 199, 1379-1390.

Shi, T., Moulton, V. R., Lapchak, P. H., Deng, G. M., le Lucca, J. J., and Tsokos, G. C. (2009). Ischemiamediated aggregation of the actin cytoskeleton is one of the major initial events resulting in ischemiareperfusion injury. Am. J. Physiol. Gastrointest. Liver Physiol. 296, G339-G347.

Song, D., Zhou, W., Sheerin, S. H., and Sacks, S. H. (1998). Compartmental localization of complement component transcripts in the normal human kidney. Nephron 78, 15-22.

Stover, C. M., Lynch, N. J., Hanson, S. J., Windbichler, M., Gregory, S. G., and Schwaeble, W. J. (2004). Organization of the MASP2 locus and its expression profile in mouse and rat. Mamm. Genome 15, 887-900.

Takada, M., Nadeau, K. C., Shaw, G. D., Marquette, K. A., and Tilney, N. L. (1997). The cytokineadhesion molecule cascade in ischemia/reperfusion injury of the rat kidney. Inhibition by a soluble P-selectin ligand. J. Clin. Invest. 99, 2682-2690.

Thiel, S. (2007). Complement activating soluble pattern recognition molecules with collagen-like regions, mannan-binding lectin, ficolins and associated proteins. Mol. Immunol. 44, 3875-3888.

Thiel, S., Vorup-Jensen, T., Stover, C. M., Schwaeble, W., Laursen, S. B., Poulsen, K., et al. (1997). A second serine protease associated with mannan-binding lectin that activates complement. Nature 386, 506-510.

Thurman, J. M., Ljubanovic, D., Edelstein, C. L., Gilkeson, G. S., and
Holers, V. M. (2003). Lack of a functional alternative complement pathway ameliorates ischemic acute renal failure in mice. J. Immunol. 170, 1517-1523.

Thurman, J. M., Ljubanovic, D., Royer, P. A., Kraus, D. M., Molina, H., Barry, N. P., et al. (2006). Altered renal tubular expression of the complement inhibitor Crry permits complement activation after ischemia/reperfusion. J. Clin. Invest. 116, 357-368.

Thurman, J. M., Lucia, M. S. Ljubanovic, D., and Holers, V. M. (2005). Acute tubular necrosis is characterized by activation of the alternative pathway of complement. Kidney Int. 67, 524-530.

Turner, M. W. (2003). The role of mannose-binding lectin in health and disease. Mol. Immunol. 40, 423-429.

van der Pol, P., Schlagwein, N. van Gijlswijk, D. J., Berger, S. P., Roos, A., Bajema, I. M., et al. (2012). Mannan-binding lectin mediates renal ischemia/reperfusion injury independent of complement activation. Am. J. Transplant. 12, 877-887.

Vorup-Jensen, T., Petersen, S. V., Hansen, A. G., Poulsen, K., Schwaeble, W., Sim, R. B., et al. (2000). Distinct pathways of mannan-binding lectin (MBL)- and C1-complex autoactivation revealed by reconstitution of $\mathrm{MBL}$ with recombinan MBL-associated serine protease- 2 . J. Immunol. 165, 2093-2100.

Wagner, S., Lynch, N. J., Walter, W., Schwaeble, W. J., and Loos, M. (2003). Differential expression of the murine mannose-binding lectins $\mathrm{A}$ and $\mathrm{C}$ in lymphoid and nonlymphoid organ and tissues. J. Immunol. 170, 1462 1465.

Walsh, M. C., Bourcier, T., Takahashi, K., Shi, L., Busche, M. N., Rother, R. P., et al. (2005). Mannose-binding lectin is a regulator of inflammation that accompanies myocardial ischemia and reperfusion injury. $J$ Immunol. 175, 541-546.

Weiser, M. R., Williams, J. P., Moore, F. D. Jr., Kobzik, L., Ma, M., Hechtman, H. B., et al. (1996). Reperfusion injury of ischemic skeletal muscle is mediated by natural antibody and complement. J. Exp. Med. 183, 23432348.

Weisman, H. F., Bartow, T., Leppo, M. K., Marsh, H. C. Jr., Carson, G. R., Concino, M. F., et al. (1990). Soluble human complement receptor type 1: in vivo inhibitor of complement suppressing post-ischemic myocardial inflammation and necrosis. Science 249, 146-151.

Williams, J. P., Pechet, T. T., Weiser, M. R., Reid, R., Kobzik, L., Moore, F. D.
Jr., et al. (1999). Intestinal reperfusion injury is mediated by $\operatorname{IgM}$ and complement. J. Appl. Physiol. 86, 938-942.

Zhang, M., Alicot, E. M., Chiu, I., Li, J., Verna, N., Vorup-Jensen, T., et al. (2006). Identification of the target self-antigens in reperfusion injury. $J$. Exp. Med. 203, 141-152.

Zhang, M., Takahashi, K., Alicot, E. M., Vorup-Jensen, T., Kessler, B., Thiel, S., et al. (2006). Activation of the lectin pathway by natural IgM in a model of ischemia/reperfusion injury. J. Immunol. 177, 4727-4734.

Zhang, M., Austen, W. G. Jr., Chiu, I., Alicot, E. M., Hung, R., Ma, M., et al. (2004). Identification of a specific self-reactive IgM antibody that initiates intestinal ischemia/reperfusion injury. Proc. Natl. Acad. Sci. U.S.A. 101, 3886-3891.

Zhao, H., Montalto, M. C., Pfeiffer, K. J., Hao, L., and Stahl, G. L. (2002). Murine model of gastrointestinal ischemia associated with complement-dependent injury. J. Appl. Physiol. 93, 338-345.

Zhou, W., Farrar, C. A., Abe, K., Pratt, J. R., Marsh, J. E., Wang, Y., et al. (2000). Predominant role for C5b-9 in renal ischemia/reperfusion injury. J. Clin. Invest. 105, 1363-1371.

Zhou, W., Campbell, R. D., Martin, J., and Sacks, S. H. (1993). Interferongamma regulation of $\mathrm{C} 4$ gene expression in cultured human glomerular epithelial cells. Eur. J. Immunol. 23, 2477-2481.

Conflict of Interest Statement: The authors declare that the research was conducted in the absence of any commercial or financial relationships that could be construed as a potential conflict of interest.

Received: 20 June 2012; accepted: 25 October 2012; published online: 19 November 2012.

Citation: Farrar CA, Asgari E, Schwaeble WJ and Sacks SH (2012) Which pathways trigger the role of complement in ischemia/reperfusion injury? Front. Immun. 3:341. doi: 10.3389/fimmu. 2012.00341

This article was submitted to Frontiers in Molecular Innate Immunity, a specialty of Frontiers in Immunology.

Copyright (C) 2012 Farrar, Asgari, Schwaeble and Sacks. This is an openaccess article distributed under the terms of the Creative Commons Attribution License, which permits use, distribution and reproduction in other forums, provided the original authors and source are credited and subject to any copyright notices concerning any third-party graphics etc. 